\title{
Investigating the effects of virtual social networks on entrepreneurial marketing
}

\author{
Kambeiz Talebi $^{a}$, Mahnaz Behrad ${ }^{b^{*}}$ and Amir Ekhlassi ${ }^{\mathrm{c}}$
}

\begin{abstract}
${ }^{a}$ Associate professor, Faculty of Entrepreneurship, University of Tehran, Tehran, Iran
${ }^{b}$ Student, Faculty of Entrepreneurship, University of Tehran, Tehran, Iran

${ }^{c}$ Assistant Professor, Faculty of Entrepreneurship, University of Tehran, Tehran, Iran

\section{H R O N I C L E}

\section{A B S T R A C T}

Article history:

Received January 20, 2014

Accepted 30 August 2014

Available online

September 152014

Virtual social networks

Entrepreneurial marketing

Structural Virtual Social Network

Interaction Virtual Social Network

Functional Virtual Social Network
This paper presents an empirical investigation to study the effects of virtual social networks on entrepreneurial marketing. The study designs a questionnaire in Likert scale based on a model originally developed by Morris et al. (2002) [Morris, M. H., Schindehutte, M., \& LaForge, R. W. (2002). Entrepreneurial marketing: a construct for integrating emerging entrepreneurship and marketing perspectives. Journal of Marketing Theory and Practice, 10(4), 1-19.]. The study considers the effects of three components of virtual social network (VSN); namely structural VSN, interaction VSN and functional VSN on entrepreneurial marketing. Using structural equation modeling, the study has determined positive and meaningful effects of all three VSN components on entrepreneurial marketing.

\section{Introduction}

The term entrepreneurial marketing (EM) (Gilmore \& Carson, 1999) is normally applied as an integrative conceptualization, which reflects such alternative perspectives as radical marketing, expeditionary marketing, etc. (Cromie, 1995; Carson, 1985; Collinson \& Shaw, 2001; Davis et al., 1985). There are always some concerns on investigating the effects of trust and privacy on social pages (Dwyer et al., 2007; Fu, 2007). Morris et al. (2002) are believed to be the first who critically explored the construct of EM. They determined seven core dimensions of EM and proposed an underlying theoretical foundation based on resource advantage theory. They also introduced a conceptual model for key factors influencing the phenomenon of entrepreneurial marketing. Networking is one means through which owner-managers of small companies market their products (O'Donnell, 2014; Hill \& Wright, 2001). Greve and Salaff (2003) studied network activities of entrepreneurs through three phases of building a company in four different countries. Entrepreneurs access people in their networks to study perspectives of building and running a business. They reported that entrepreneurs build networks that systematically change by the phase of entrepreneurship, investigating number of their discussion partners, and the time spent networking. BarNir and Smith (2002) explored whether the social network of small business executives could be *Corresponding author.

E-mail addresses: mahnazbehrad86@gmail.com (M. Behrad) 
leveraged to facilitate the establishment of inter-firm alliances. According to Ellison (2007) proposed a comprehensive definition for Social network sites and presented one perspective on the history of such sites, investigating key changes and developments. Fu et al. (2008) demonstrated that both networks possess small-world and scale-free features could be observed in real-world and artificial networks. Stringhini et al. (2010) proposed a model to detect spammer in cyber space. Harris and Rae (2009) investigated the recent developments in online marketing strategy, which represent the growing power of online communities in building brand reputations and customer relationships. They concluded that social networks would play an essential role in the future of marketing and they could replace customer annoyance with engagement. Hills et al. (2008) investigated the evolution of entrepreneurial marketing (EM). They provided a summary of how EM had evolved into a potential new school of marketing thought and offered several issues, which could stimulate future research in EM. Entrepreneurs receive information and support more easily if they have different ties with redundant relations (Jenssen \& Greve, 2002; Li \& Bernoff, 2011). Talebi (2007) reported that the main causes of the weakness and disability of the SMEs were the lack of entrepreneurship talents and training. Subrahmanyam et al. (2008) reported that participants often used the Internet, especially social networking sites, to connect and reconnect with friends and family members.

\section{The proposed study}

This paper presents an empirical investigation to study the effects of virtual social networks on entrepreneurial marketing. The study designs a questionnaire in Likert scale based on a model originally developed by Morris et al. (2002). The study considers the effects of three components of virtual social network (VSN); namely structural VSN, interaction VSN and functional VSN on entrepreneurial marketing. The main hypothesis of the survey is as follows (See Fig. 1),

Main hypothesis: Virtual social network influences positively on entrepreneurial marketing. The study also considers the following three sub-hypotheses,

1. Structural virtual social network influences positively on entrepreneurial marketing.

2. Interaction virtual social network influences positively on entrepreneurial marketing.

3. Functional virtual social network influences positively on entrepreneurial marketing.

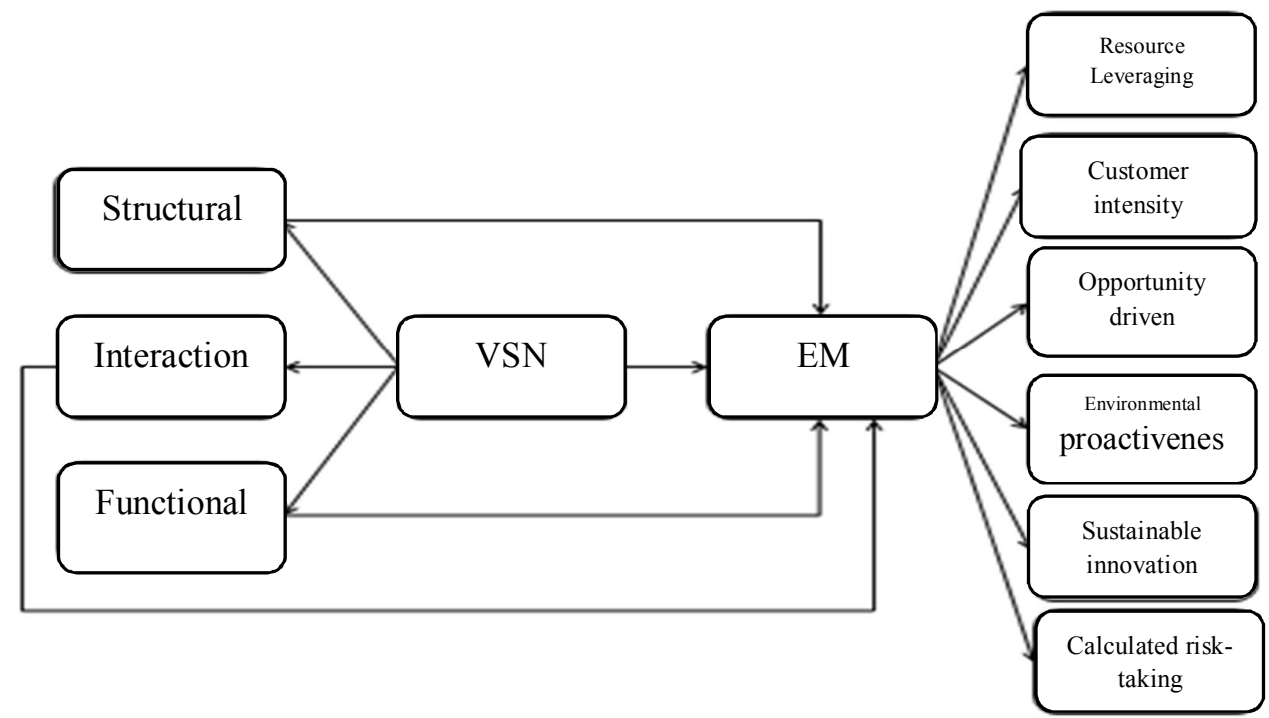

Fig. 1. The proposed study

Table 1 demonstrates the summary of all variables involved for the proposed study of this paper. 
Table 1

The summary of variables for the proposed study

\begin{tabular}{ccc}
\hline The first level of latent variables & The second level of latent variables & Number of \\
\hline \multirow{2}{*}{ Virtual Social Network } & SVSN( Structural Virtual Social Network), & 9 \\
& IVSN( Interaction Virtual Social Network) & 10 \\
& FVSN( Functional Virtual Social Network) & 14 \\
\hline Entrepreneurial marketing & Resource Leveraging(EM1) & 3 \\
& Customer intensity(EM2) & 3 \\
& Opportunity driven(EM3) & 3 \\
& Environmental proactiveness(EM4) & 2 \\
\hline
\end{tabular}

The population of this study includes all small and medium entrepreneurial marketing units, which are active in Iran. Therefore, the sample size is calculated as follows,

$$
N=Z_{\alpha / 2}^{2} \frac{p \times q}{e^{2}},
$$

where $N$ is the sample size, $p=1-q$ represents the probability, $z_{\alpha / 2}$ is CDF of normal distribution and finally $\varepsilon$ is the error term. For our study we assume $p=0.5, z_{\alpha / 2}=1.96$ and $e=0.05$, the number of sample size is calculated as $N=384$. We first distributed a limited number of questionnaires among some selected experts. Table 2 demonstrates the summary of Cronbach alphas.

\section{Table 2}

The summary of Cronbach alpha

\begin{tabular}{cccccc}
\hline Perspective & Cronbach & Composite & Sub-factor & Cronbach & Composite \\
\hline Virtual Social & \multirow{2}{*}{0.89} & \multirow{2}{*}{0.9} & SVSN & 0.7 & 0.78 \\
Network & & & IVSN & 0.71 & 0.78 \\
& & & FVSN & 0.9 & 0.91 \\
\hline & \multirow{2}{*}{0.91} & Resource Leveraging (EM1) & 0.7 & 0.86 \\
Entrepreneurial & \multirow{2}{*}{0.89} & & Customer intensity (EM2) & 0.76 & 0.84 \\
marketing & & & Opportunity driven (EM3) & 0.8 & 0.86 \\
& & & Sustainable innovation (EM5) & 0.74 & 0.71 \\
\end{tabular}

As we can observe from the results of Table 2, all components of the survey are well above the minimum acceptable level. In addition, all average variance extracted are well above 0.4 in our survey, which means the study has good fitness.

\section{The results}

In this section, we present details of our findings on testing the main and three sub-hypotheses of the survey. Fig. 2 shows the summary of the implementation of structural equation modeling for testing the main hypothesis of the survey. As we can observe from the results of Fig. 2, all components maintain meaningful t-student values when the level of significance was five percent. In addition, there are positive relationship between VSN and EM. Therefore, the main hypothesis of the survey has been confirmed. We have also examined the sub-hypotheses of the survey and Fig. 3 shows details of our findings on testing the sub-hypotheses of the survey. 


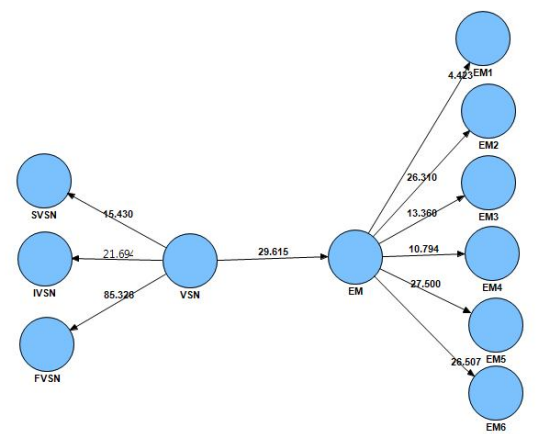

The results of t-values

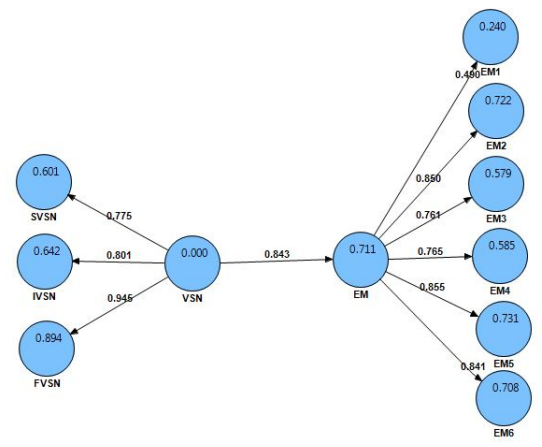

The results of path coefficients

Fig. 2. The results of the implementation of structural equation modeling for testing the main hypothesis of the survey

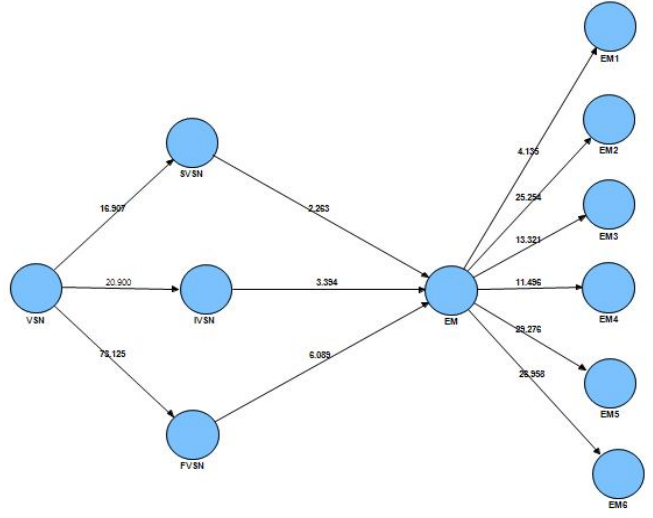

The results of t-values

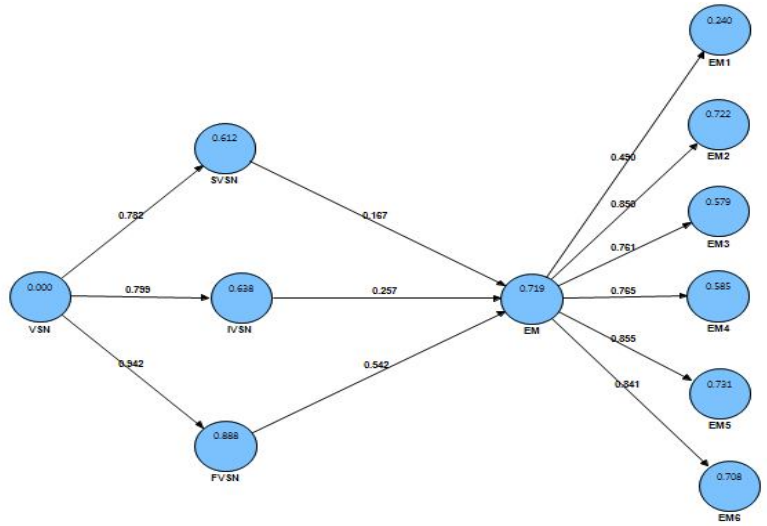

The results of path coefficients

Fig. 3. The results of the implementation of structural equation modeling for testing the subhypotheses of the survey

Again, the results of Fig. 3 show that all components had meaningful t-student values when the level of significance was five percent. In addition, there are positive relationship between VSN and EM. Therefore, the main hypothesis of the survey has been confirmed. The results indicate that $17 \%$ of the changes on EM is described by SVSN, $26 \%$ of the changes are described by IVSN and finally, $54 \%$ of the changes are described by FVSN.

\section{Conclusion}

In this paper, we have presented an empirical investigation to study the effects of virtual social network on entrepreneurial marketing for selected small and medium enterprises in Iran. The study has adopted the existing questionnaire in the literature and using structural equation modeling, the study has confirmed a positive and meaningful relationship between these two components.

The survey has also confirmed that $17 \%$ of the changes on entrepreneurial marketing was represented by SVSN, 26\% of the changes are described by IVSN and finally, 54\% of the changes are described by FVSN. The results of this survey are consistent with findings of Gilmore et al. (2006), Harris and Rae (2009), Hill and Wright (2001), Jones and Rowley (2011), Hills and LaForge (1992), Kristiansen (2004) and Hills et al. (2010). 


\section{Acknowledgement}

The authors would like to thank the anonymous referees for constructive comments on earlier version of this paper.

\section{References}

BarNir, A., \& Smith, K. A. (2002). Interfirm alliances in the small business: The role of social networks. Journal of Small Business Management, 40(3), 219-232.

Carson, D. J. (1985). The evolution of marketing in small firms. European Journal of Marketing, 19(5), 7-16.

Collinson, E., \& Shaw, E. (2001). Entrepreneurial marketing-a historical perspective on development and practice. Management decision, 39(9), 761-766.

Cromie, S., McGowan, P., \& Hill, J. (1995). Marketing and entrepreneurship in SMEs: an innovative approach (Vol. 1). London: Prentice Hall.

Davis, C. D., Hills, G. E., \& LaForge, R. W. (1985). The marketing/small enterprise paradox: a research agenda. International Small Business Journal,3(3), 31-42.

Dwyer, C., Hiltz, S., \& Passerini, K. (2007). Trust and privacy concern within social networking sites: A comparison of Facebook and MySpace. AMCIS 2007 Proceedings, 339.

Ellison, N. B. (2007). Social network sites: Definition, history, and scholarship. Journal of ComputerMediated Communication, 13(1), 210-230.

Fu, B. (2007). Trust Management in Online Social Networks (Doctoral dissertation, University of Dublin, Trinity College).

Fu, F., Liu, L., \& Wang, L. (2008). Empirical analysis of online social networks in the age of Web 2.0. Physica A: Statistical Mechanics and its Applications,387(2), 675-684.

Gilmore, A., \& Carson, D. (1999). Entrepreneurial marketing by networking. New England Journal of Entrepreneurship, 2(2), 31-38.

Gilmore, A., Carson, D., \& Rocks, S. (2006). Networking in SMEs: Evaluating its contribution to marketing activity. International Business Review, 15(3), 278-293.

Greve, A., \& Salaff, J. W. (2003). Social networks and entrepreneurship. Entrepreneurship theory and practice, 28(1), 1-22.

Harris, L., \& Rae, A. (2009). Social networks: the future of marketing for small business. Journal of business strategy, 30(5), 24-31.

Hills, G. E., \& LaForge, R. W. (1992). Research at the marketing interface to advance entrepreneurship theory. Entrepreneurship Theory and Practice, 16(3), 33-59.

Hill, J., \& Wright, L. T. (2001). A qualitative research agenda for small to medium-sized enterprises. Marketing Intelligence \& Planning, 19(6), 432-443.

Hills, G. E., Hultman, C. M., \& Miles, M. P. (2008). The evolution and development of entrepreneurial marketing. Journal of Small Business Management, 46(1), 99-112.

Hills, G. E., Hultman, C. M., Kraus, S., \& Schulte, R. (2010). History, theory and evidence of entrepreneurial marketing-an overview. International Journal of Entrepreneurship and Innovation Management, 11(1), 3-18.

Jenssen, J. I., \& Greve, A. (2002). Does the degree of redundancy in social networks influence the success of business start-ups?. International Journal of Entrepreneurial Behaviour \& Research, 8(5), 254-267.

Jones, R., \& Rowley, J. (2011). Entrepreneurial marketing in small businesses: a conceptual exploration. International Small Business Journal, 29(1), 25-36.

Kristiansen, S. (2004). Social networks and business success. American journal of economics and sociology, 63(5), 1149-1171.

Li, C., \& Bernoff, J. (2011). Groundswell: Winning in a world transformed by social technologies. Harvard Business Press. 
O'Donnell, A. (2014). The contribution of networking to small firm marketing. Journal of Small Business Management, 52(1), 164-187.

Morris, M. H., Schindehutte, M., \& LaForge, R. W. (2002). Entrepreneurial marketing: a construct for integrating emerging entrepreneurship and marketing perspectives. Journal of marketing theory and practice, 10(4), 1-19.

Stringhini, G., Kruegel, C., \& Vigna, G. (2010, December). Detecting spammers on social networks. In Proceedings of the 26th Annual Computer Security Applications Conference (pp. 1-9). ACM.

Subrahmanyam, K., Reich, S. M., Waechter, N., \& Espinoza, G. (2008). Online and offline social networks: Use of social networking sites by emerging adults. Journal of Applied Developmental Psychology, 29(6), 420-433.

Talebi, K. (2007). Entrepreneurship and SMEs Business Environment in Iran. Journal of Entrepreneurship Research, 1(1), 139-154. 